\title{
An Adult Case of Bartter Syndrome Type III Presenting with Proteinuria
}

\author{
Eun Jung Cha · Won Min Hwang ${ }^{1}$ \\ Sung-Ro Yun ${ }^{1} \cdot$ Moon Hyang Park \\ Department of Pathology, ${ }^{1}$ Division of \\ Nephrology, Department of Internal Medicine, \\ Konyang University Hospital, Konyang University \\ College of Medicine, Daejeon, Korea \\ Received: June 12, 2015 \\ Revised: August 4, 2015 \\ Accepted: August 31, 2015 \\ Corresponding Author \\ Moon Hyang Park, MD \\ Department of Pathology, Konyang University \\ Hospital, Konyang University College of Medicine \\ 158 Gwanjeodong-ro, Seo-gu, Daejeon 35365, \\ Korea \\ Tel: +82-42-600-9280 \\ Fax: +82-42-600-9280 \\ E-mail: parkmh@hanyang.ac.kr
}

Bartter syndrome (BS) I-IV is a rare autosomal recessive disorder affecting salt reabsorption in the thick ascending limb of the loop of Henle. This report highlights clinicopathological findings and genetic studies of classic BS in a 22-year-old female patient who presented with persistent mild proteinuria for 2 years. A renal biopsy demonstrated a mild to moderate increase in the mesangial cells and matrix of most glomeruli, along with marked juxtaglomerular cell hyperplasia. These findings suggested BS associated with mild IgA nephropathy. Focal tubular atrophy, interstitial fibrosis, and lymphocytic infiltration were also observed. A genetic study of the patient and her parents revealed a mutation of the CLCNKB genes. The patient was diagnosed with BS, type III. This case represents an atypical presentation of classic BS in an adult patient. Pathologic findings of renal biopsy combined with genetic analysis and clinicolaboratory findings are important in making an accurate diagnosis.

Key Words: Bartter syndrome; Hypokalemia; Juxtaglomerular cell hyperplasia
Bartter syndrome (BS) is a rare renal tubulopathy that was first described by Bartter in 1962. ${ }^{1}$ The condition is characterized by polyuria, hypokalemia, metabolic alkalosis, and hyperreninemic-hyperaldosteronism with normal or slightly low blood pressure due to renal loss of sodium and hyperplasia of the juxtaglomerular apparatus (JGA). The condition is also referred to as salt-wasting nephropathy. ${ }^{1}$ The prevalence of BS is 1 in 1,000,000, compared with 1 in 40,000 for Gitelman syndrome (GS). ${ }^{2}$ The classification depends on the severity of the symptoms and type of genetic mutation. Clinically, BS can be classified into two variants, antenatal/neonatal BS and classic BS, according to the onset of age. Genetically, BS can be classified into five variants according to type of gene mutation. ${ }^{3}$ Type III BS presents as classic BS, which is characterized by polyuria, polydipsia, and a tendency for dehydration, but with normal or slightly increased urinary calcium excretion and no tendency to develop kidney stones. Patients with classic BS might have symptoms in the first two years of life, but most cases are usually diagnosed at school age or in adolescence. ${ }^{4}$ However, age of onset and clinical severity are highly variable. ${ }^{5-7}$

Here, we present a case of late onset BS, with typical hyperplasia of juxtaglomerular cells on renal biopsy and molecular di- agnostic confirmation of a familial chloride channel $\mathrm{Kb}(C L C N K B)$ gene mutation.

\section{CASE REPORT}

Mild proteinuria had been incidentally detected in a 22-yearold woman during a regular health check-up 2 years prior to presentation. She visited a local clinic for a follow-up check. She took medication to treat hyperlipidemia for 1 year and did not take any other drugs including diuretics or laxatives. She was admitted to our hospital for evaluation of persistent mild proteinuria.

The prenatal course was unremarkable. On physical examination, her height was $153 \mathrm{~cm}$, her body weight was $49 \mathrm{~kg}$ and her blood pressure was 100/60 mm Hg. No edema was found, and normal muscle strength and reflexes were noted. The rest of the physical examination was unremarkable. The laboratory examination revealed blood urea nitrogen of $10.9 \mathrm{mg} / \mathrm{dL}$, creatinine of $0.68 \mathrm{mg} / \mathrm{dL}$, sodium of $137 \mathrm{mmol} / \mathrm{L}$, potassium of 2.59 $\mathrm{mmol} / \mathrm{L}$, chloride of $94.7 \mathrm{mmol} / \mathrm{L}$, magnesium of $2.05 \mathrm{mEq} / \mathrm{L}$, and bicarbonate of $31.2 \mathrm{mEq} / \mathrm{L}$. Serum levels of $\operatorname{IgG}, \operatorname{IgA}, \operatorname{IgM}$, C3, and C4 were normal. Anti-nuclear antibody was negative. Urinalysis showed a specific gravity of 1.007 , trace protein, $\mathrm{pH}$ 
8.0, and no red blood cells. The spot urine protein/creatinine ratio was $0.95 \mathrm{~g} / \mathrm{g}$ creatinine. Abdominal sonography revealed normal-sized kidneys, without nephrocalcinosis or stones. Plasma renin activity was elevated at $27.98 \mathrm{ng} / \mathrm{mL} / \mathrm{hr}$ (normal range, 0.50 to $1.90 \mathrm{ng} / \mathrm{mL} / \mathrm{hr}$ in a supine position), but serum aldosterone was $13.2 \mathrm{pg} / \mathrm{mL}$ within normal limits (normal range, 1 to $16 \mathrm{pg} / \mathrm{mL}$ in a supine position). The urine prostaglandin E2 level was elevated at $2,815 \mathrm{ng} /$ day (normal range, 400 to 620 ng/day). These findings suggested BS or pseudo-BS/GS caused by vomiting or diuretics.

Light microscopy of renal biopsy demonstrated 14 glomeruli, two of which were globally sclerotic. Most glomeruli appeared moderately increased in size and cellularity due to prominence of the mesangium and JGA. Five glomeruli showed marked enlargement with hyperplasia (Fig. 1A) and hypergranulosis of the JGA (Fig. 1B). The mesangium was diffusely expanded due to mild to moderate increase in cells and matrix (Fig. 1A). There was moderate tubular atrophy and interstitial fibrosis with infiltration of lymphocytes. The interlobular arteries and arterioles displayed mild to moderate intimal fibrous thickening and medial sclerosis. Immunofluorescence revealed weak positive $(1+)$ staining for $\operatorname{IgG}, \operatorname{IgA}$, and fibrinogen and trace $(+/-)$ of staining for $\mathrm{C} 3$ and lambda in the mesangium (Fig. 1C). Electron microscopy revealed mild increase in the mesangial cells and matrix with rare small mesangial electron-dense deposits and hyperplastic juxtaglomerular cells with increased electron dense renin and progranules (Fig. 1D).

Genetic analysis revealed a homozygous deletion of exon 1-14 and heterozygous deletion of exon 15-19 in the CLCNKB gene (Fig. 2A). Her father had heterozygous deletion of exon 1-14 (Fig. 2B), and her mother had heterozygous deletion of all examined exons of the CLCNKB gene (Fig. 2C). However, her
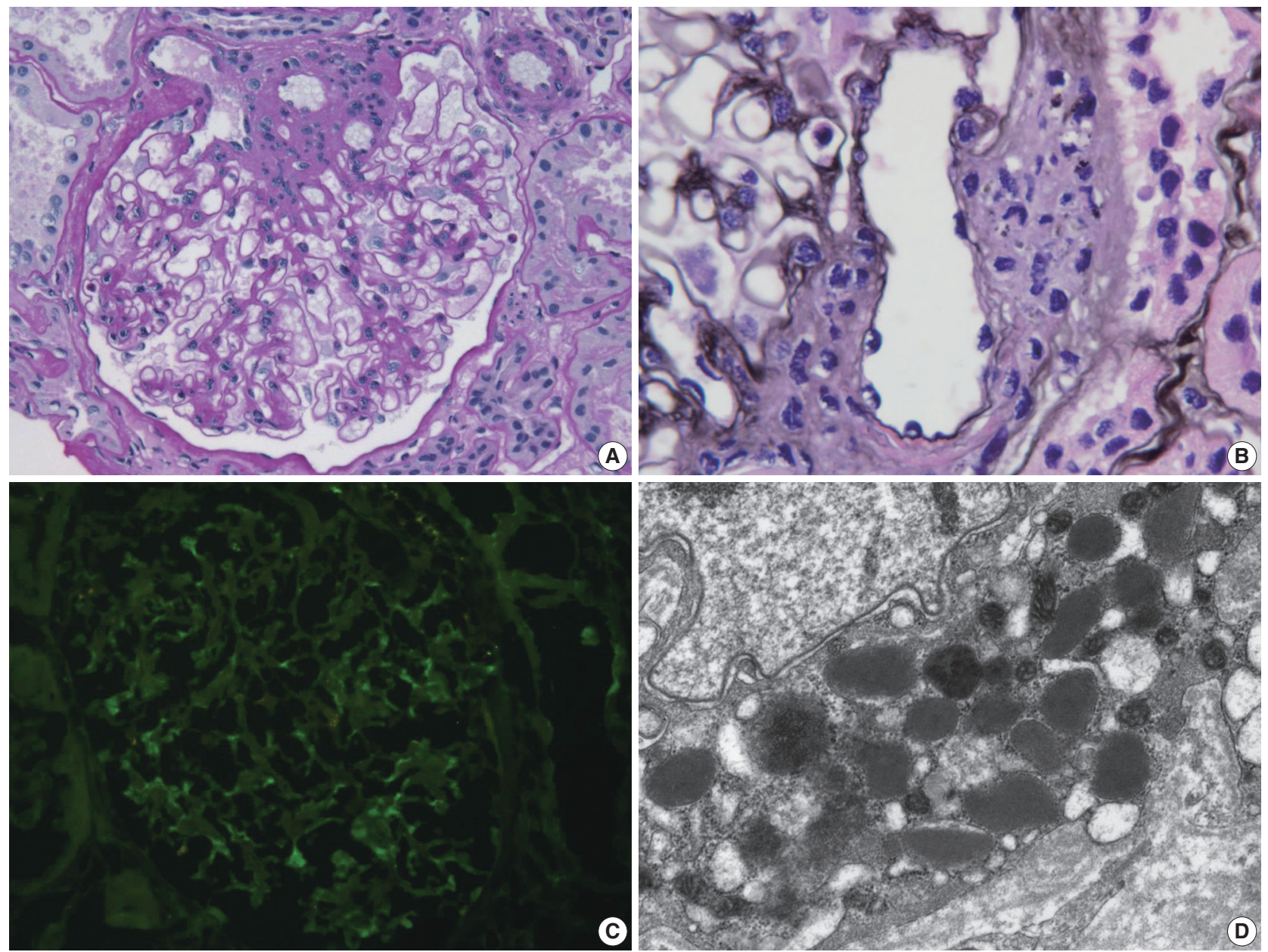

Fig. 1. Renal biopsy in a patient with Bartter syndrome with IgA nephropathy. (A) Glomerulus shows hyperplasia of juxtaglomerular cells with increased mesangial cells and matrix (periodic acid-Schiff). (B) Glomerulus shows hyperplasia and hypergranulosis of juxtaglomerular cells (Jones' methenamine silver, $\times 1,000$ ). (C) Immunofluorescence reveals weak (1+) staining for IgA in the mesangium. (D) Electron micrograph of the juxtraglomerular apparatus shows abundant progranules and mature renin granules (Hitach HT7700 EM, ×6,000). 


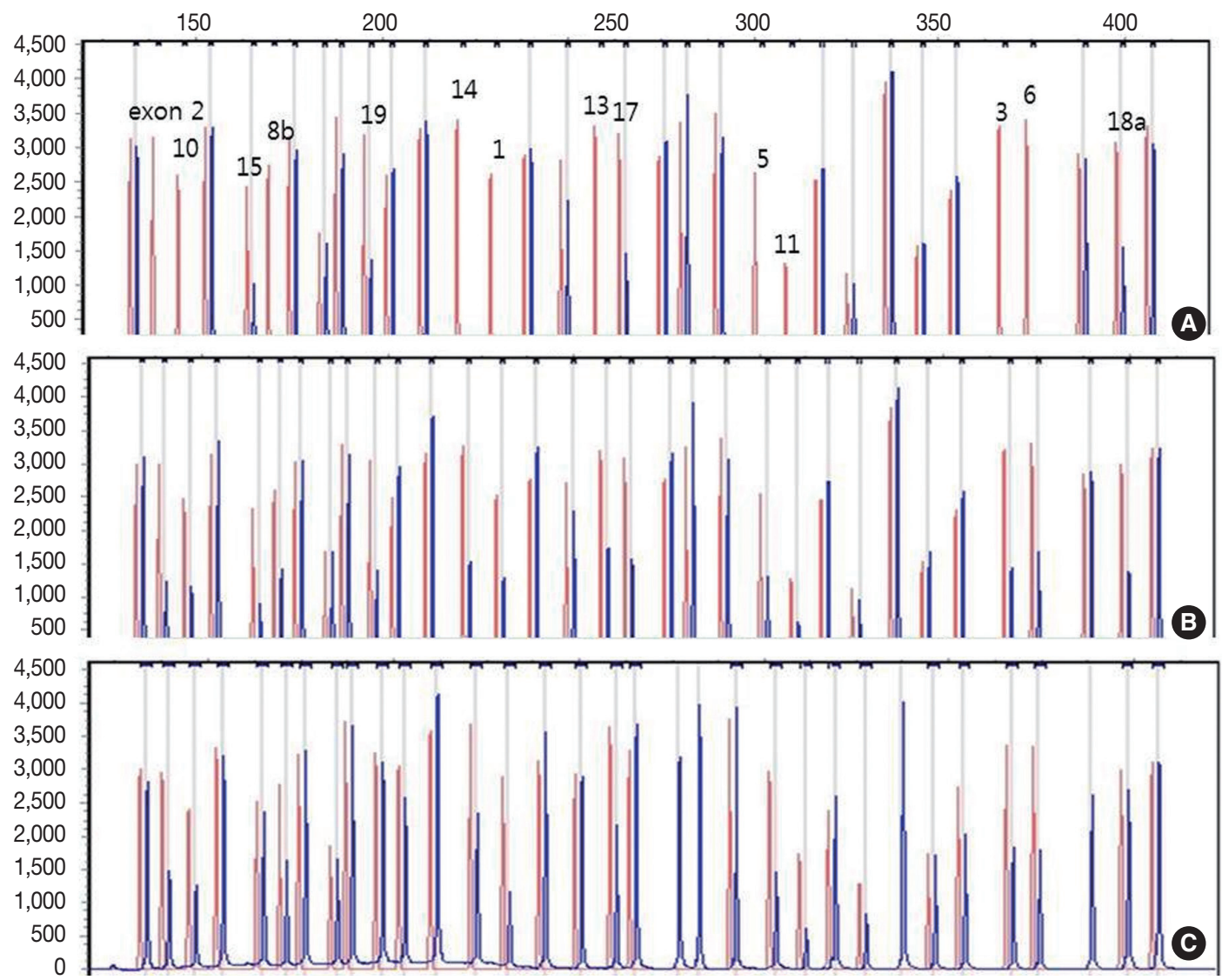

Fig. 2. Capillary electrophoretic pattern of the multiplex ligation-dependent probe amplification products of the patient's family. (A) The patient has a large homozygous deletion and a large heterozygous deletion. (B) Her father has a heterozygous deletion of exon 1-14. (C) Her mother has a heterozygous deletion of all examined exons of the CLCNKB gene.

parents displayed no renal symptoms or abnormal renal function.

\section{DISCUSSION}

BS is an autosomal recessive genetic disorder whose primary pathogenic mechanism is defective transepithelial chloride reabsorption in the thick ascending limb of the loop of Henle. The disorder is the result of defective function of proteins responsible for transporting ions to renal cells. Five types of genetic mutations are associated with the five different forms of the disease. Type I is due to an SLC12A1 mutation encoding the bumetanide-sensitive $\mathrm{Na}^{+}-\mathrm{K}^{+}-2 \mathrm{Cl}^{-}$cotransporter (NKCC2), and type II is the result of KCNJ1 encoding the inward rectifying $\mathrm{K}^{+}$channel (ROMK). Type III or classic BS results from a mutation of CLCNKB, encodes for the kidney-specific basolateral chloride channel $(\mathrm{CIC}-\mathrm{Kb})$. The $\mathrm{CIC}-\mathrm{Kb}$ protein is required to ensure the exit of chloride $\left(\mathrm{Cl}^{-}\right)$on the basolateral side. Impaired $\mathrm{CIC}$ $\mathrm{Kb}$ function reduces $\mathrm{Cl}^{-}$efflux and decreases $\mathrm{Na}-\mathrm{K}-\mathrm{Cl}$ reabsorption through NKCC2 by modifying the transepithelial voltage gradient and causing salt loss in urine. ${ }^{4}$ Type IV is due to mutations of $B S N D$ encoding barttin (the $\beta$-subunit of the basolateral chloride channel). Finally, type V, with the features of autosomal dominant hypocalcemia, is caused by gain-of-function mutations of the calcium-sensing receptor. ${ }^{3,5,8,9}$ Types I, II, and IV are classified as antenatal BS.

Renal calcium handling can be used to differentiate between classic BS and GS. Hypomagnesemia is considered a well-defined characteristic of GS but it also affects a considerable number of patients with BS. The most definitive diagnostic method of BS is molecular analysis. ${ }^{10,11}$ The patient in the current case had no symptoms in the neonatal period or in childhood. This patient had no symptoms of polyuria, dehydration, or polydipsia except for nocturia and presented with mild proteinuria and mild hypokalemic metabolic alkalosis at 22 years of age. Clinically, this patient's diagnosis raised a suspicion of GS rather than BS, but deletion of the CLCNKB gene in the genetic analysis confirmed type III BS.

Although proteinuria is not a classic symptom in BS, it has 
been a presenting symptom in cases associated with other glomerular diseases, such as focal segmental glomerulosclerosis, C1q nephropathy or immune complex glomerulopathy. ${ }^{12-15}$ Our patient had mild proteinuria for 2 years. The presence of mild to moderate mesangial proliferation in the renal biopsy, in addition to the weak positive immunofluorescence staining for $\operatorname{Ig} \mathrm{A}$ in the mesangium pointed to the possibility of mild IgA nephropathy coexistent with BS. Electron microscopy revealed rare small paramesangial electron dense deposits.

Renal changes in BS are probably caused by stimulation of the renin-angiotensin axis and activation of transforming growth factor $\beta$ (TGF- $\beta$ ). ${ }^{16}$ Laboratory studies have suggested that exposure of mesangial cells to angiotensin II results in proliferation, hypertrophy, and TGF- $\beta$ production. ${ }^{13}$ Although patients with BS have high angiotensin II level and activation of the renin-angiotensin axis, they also demonstrate normo/hypotension, reduced peripheral resistance, and hyporesponsiveness to vasopressor agents. Patients with BS and GS, as well as heterozygous carriers of both disorders, have lower blood pressure than the general population. ${ }^{2}$ In addition to volume depletion, another possible contributor to the lower blood pressure in BS is increased renal release of vasodilator prostaglandins E2 (PGE2). The increased renal production of PGE2 results from impaired entry of sodium chloride into the macula densa cells at the end of the thick ascending limb of the loop of Henle, which increases the expression of cyclooxygenase $2 .{ }^{17}$ Therefore, these patients do not develop hypertension or associated complications such as cardiovascular remodeling and atherogenesis. ${ }^{18}$ The cause of renal dysfunction in patients with BS is unclear.

The histologic and molecular features of BS have been well described in the literature, ${ }^{3,5,6}$ and histologic findings of BS consistently show juxtaglomerular hyperplasia, interstitial fibrosis and nephrocalcinosis. Juxtaglomerular hyperplasia is a characteristic finding but is not a necessary finding for diagnosis. Juxtaglomerular hyperplasia can be associated with a variety of causes, such as chronic hypovolemic states with hypokalemia due to chronic vomiting or laxative abuse, familial chloride diarrhea, or cystinosis. ${ }^{4}$ The ingestion of diuretics is perhaps the most common cause of chronic hypokalemic alkalosis. For an accurate diagnosis, other causes must be rule out through careful history taking, plasma and urine electrolyte measurement, or various diuretic screening methods. ${ }^{19}$

Accounting for the patient's clinical, laboratory, and pathological findings of BS, in conjunction with the results of genetic analysis of both the patient and her parents, the patient was diagnosed with type III BS. This case shows the importance of renal biopsy and molecular analysis in delineating the cause of an atypical presentation of classic BS in an adult patient.

\section{Conflicts of Interest}

No potential conflict of interest relevant to this article was reported.

\section{Acknowledgments}

We thank Prof. Haell Cheong for performing the genetic study.

\section{REFERENCES}

1. Bartter FC, Pronove P, Gill JR Jr, Maccardle RC. Hyperplasia of the juxtaglomerular complex with hyperaldosteronism and hypokalemic alkalosis: a new syndrome. Am J Med 1962; 33: 811-28.

2. Ji W, Foo JN, O'Roak BJ, et al. Rare independent mutations in renal salt handling genes contribute to blood pressure variation. Nat Genet 2008; 40: 592-9.

3. Lee BH, Cho HY, Lee H, et al. Genetic basis of Bartter syndrome in Korea. Nephrol Dial Transplant 2012; 27: 1516-21.

4. Naesens M, Steels P, Verberckmoes R, Vanrenterghem Y, Kuypers D. Bartter's and Gitelman's syndromes: from gene to clinic. Nephron Physiol 2004; 96: p65-78.

5. Xiumin W, Zheng S, Meichun X, Junfen F, Li L. A Chinese girl with Bartter syndrome type III due to a novel mutation and/or single nucleotide polymorphisms (SNPs) in CLCNKB gene. Iran J Pediatr 2013; 23: 89-94.

6. García Castaño A, Pérez de Nanclares G, Madariaga L, et al. Genetics of type III Bartter syndrome in Spain, proposed diagnostic algorithm. PLoS One 2013; 8: e74673.

7. Simon DB, Bindra RS, Mansfield TA, et al. Mutations in the chloride channel gene, $C L C N K B$, cause Bartter's syndrome type III. Nat Genet 1997; 17: 171-8.

8. Bhat YR, Vinayaka G, Sreelakshmi K. Antenatal Bartter syndrome: a review. Int J Pediatr 2012; 2012: 857136.

9. Krämer BK, Bergler T, Stoelcker B, Waldegger S. Mechanisms of disease: the kidney-specific chloride channels ClCKA and ClCKB, the Barttin subunit, and their clinical relevance. Nat Clin Pract Nephrol 2008; 4: 38-46.

10. Knoers NV, Levtchenko EN. Gitelman syndrome. Orphanet J Rare Dis 2008; 3: 22.

11. Nakhoul F, Nakhoul N, Dorman E, Berger L, Skorecki K, Magen D. Gitelman's syndrome: a pathophysiological and clinical update. Endocrine 2012; 41: 53-7.

12. Su IH, Frank R, Gauthier BG, et al. Bartter syndrome and focal seg- 
mental glomerulosclerosis: a possible link between two diseases. Pediatr Nephrol 2000; 14: 970-2.

13. Sardani Y, Qin K, Haas M, Aronson AJ, Rosenfield RL. Bartter syndrome complicated by immune complex nephropathy: case report and literature review. Pediatr Nephrol 2003; 18: 913-8.

14. Hanevold C, Mian A, Dalton R. C1q nephropathy in association with Gitelman syndrome: a case report. Pediatr Nephrol 2006; 21: 1904-8.

15. Lee SE, Han KH, Jung YH, et al. Renal transplantation in a patient with Bartter syndrome and glomerulosclerosis. Korean J Pediatr 2011; 54: 36-9.

16. Yamamoto T, Noble NA, Cohen AH, et al. Expression of transforming growth factor-beta isoforms in human glomerular diseases.
Kidney Int 1996; 49: 461-9.

17. Kömhoff M, Reinalter SC, Gröne HJ, Seyberth HW. Induction of microsomal prostaglandin E2 synthase in the macula densa in children with hypokalemic salt-losing tubulopathies. Pediatr Res 2004; 55: 261-6.

18. Pagnin E, Davis PA, Semplicini A, Calò LA. The search for a link between inflammation and hypertension: contribution from Bartter's/Gitelman's syndromes. Nephrol Dial Transplant 2006; 21: 2340-2.

19. Colussi G, Rombolà G, Airaghi C, De Ferrari ME, Minetti L. Pseudo-Bartter's syndrome from surreptitious diuretic intake: differential diagnosis with true Bartter's syndrome. Nephrol Dial Transplant 1992; 7: 896-901. 